\title{
Métodos de Ressincronização para Sistemas de Equalização e Identificação Utilizando Marca d'Água Digital
}

\author{
Mário Uliani Neto, Leandro de C. T. Gomes e João Marcos T. Romano
}

\begin{abstract}
Resumo-Qualquer que seja a aplicação, o processo de detecção de uma marca d'água digital deve iniciar-se com a sincronização da marca no detector. Efeitos de dessincronização posteriores podem também prejudicar a detecção, potencialmente inviabilizando a extração adequada da informação contida na marca d'água. Algoritmos de ressincronização fazemse portanto necessários. Este artigo apresenta dois métodos de ressincronização para sistemas de filtragem empregando marca d'água. Ambos os métodos são baseados no uso de seqüências de treinamento embutidas na marca d'água e revertem os efeitos de uma grande classe de ataques de dessincronização. Resultados de simulação confirmam a eficiência dos métodos propostos.
\end{abstract}

Palavras-Chave-Ressincronização, marca d'água digital, identificação adaptativa, equalização adaptativa.

Abstract - In any application involving digital watermarking, initial synchronization should be the first step in the detection process. Later desynchronization can also influence the detection of the watermark, potentially making impracticable the proper extraction of the data contained therein. Resynchronization algorithms are thus necessary. This article presents two resynchronization methods for filtering systems based on watermarking. Both methods are based on the use of a training sequence that is embedded into the watermark, and are able to revert the effects of a large class of desynchronization attacks. Simulation results confirm the effectiveness of the proposed methods.

Keywords-Resynchronization, digital watermarking, adaptive identification, adaptive equalization.

\section{INTRODUÇÃO}

Para que a sua detecção seja possível, a marca d'água deve apresentar um certo grau de resistência a distorções. Em muitas aplicações, é requerida resistência a operações como filtragem, reamostragem e codificação/decodificação. Em aplicações envolvendo sistemas de comunicação, a marca d'água deve resistir a distorções que podem torná-la indetectável, tais como adição de ruído, perda ou inserção de amostras e filtragem [1].

Em geral, o processo de detecção de uma marca d'água se inicia com a sincronização (alinhamento) da marca no detector. Conforme a aplicação, um sistema utilizando marca d'água digital deve ser robusto a diferentes tipos de ataques

Mário Uliani Neto e Leandro de C. T. Gomes, Centro de Pesquisa e Desenvolvimento em Telecomunicações (CPqD), Rod. Campinas-MogiMirim (SP 340), km 118,5, CEP 13086-902, Campinas, SP, Brasil; Tel: (19) 3705-6724; e-mails: \{uliani, tgomes\} @ cpqd.com.br.

João Marcos T. Romano, DSPCom - Lab. de Proc. de Sinais para Comunicações Móveis - Fac. de Eng. Elétrica e de Computação - Universidade Estadual de Campinas (Unicamp), Caixa Postal 6101, CEP 13083-970, Campinas, SP, Brasil; Tel.: (19) 3521-3703, Fax: (19) 3289-1395; e-mail: romano@decom.fee.unicamp.br. dessincronizantes, intencionais ou não. Tais ataques dificultam a detecção apropriada da informação contida na marca d'água e podem ser difíceis de neutralizar.

Abordaremos aqui o caso de ataques não intencionais, decorrentes das distorções impostas pela transmissão do sinal marcado através de um sistema linear. Além destas distorções, consideraremos o caso de perda/inserção de trechos do sinal transmitido, acarretando deslocamentos do sinal na escala temporal.

Analisaremos dois métodos de ressincronização para marca d'água, ambos baseados no uso de seqüências de treinamento e correlação. O primeiro método utiliza a média de várias janelas de análise e o segundo um algoritmo de programação dinâmica. Estes métodos revertem os efeitos de uma grande classe de ataques de dessincronização. Além disso, são capazes de verificar o sincronismo constantemente, ao longo de todo o sinal recebido.

O artigo está estruturado como descrevemos a seguir. $\mathrm{Na}$ seção 2, são apresentados métodos de equalização e identificação supervisionados utilizando marca d'água. Na seção 3, são definidos dois métodos de ressincronização baseados em seqüência de treinamento. Na seção 4, são propostos três diferentes algoritmos capazes de localizar o atraso ótimo de sincronismo para os sistemas de equalização e identificação. Na seção 5, apresentamos algumas simulações e resultados. Finalmente, a seção 6 traz algumas conclusões e perspectivas de trabalhos futuros.

\section{EQUALIZAÇÃo E IDENTIFICAÇÃo EM Sistemas Adaptativos Utilizando Marca D' ÁGua Digital}

\section{A. Equalização Adaptativa Baseada em Marca d'Água}

A proposta de um sistema de equalização supervisionada baseada em marca d'água foi apresentada em [2], [9]. Uma marca d'água é transmitida continuamente, sobreposta ao sinal de informação, utilizando a técnica de espalhamento espectral: $s(n)=t(n)+\alpha_{m} m(n)$, onde $t(n)$ é o sinal de informação, $m(n)$ é a marca d'água e $\alpha_{m}$ é um fator de escala. A marca d'água escalonada é utilizada como sinal de referência no filtro equalizador adaptativo, produzindo uma função custo $J=E\left[|y(n)-d(n)|^{2}\right]$ que expressa o critério de Wiener [3], onde $d(n)$ é o sinal de referência e $y(n)$ o sinal na saída do equalizador. A solução é obtida através da minimização da função custo com respeito aos coeficientes do equalizador $\mathbf{w}$.

A matriz de correlação $\mathbf{R}$ de dimensão $M \times M$ na entrada do equalizador é expressa, neste caso, como: 


$$
\mathbf{R}=\alpha_{m}^{2} \mathbf{H} E\left[\mathbf{m}(n) \mathbf{m}^{T}(n)\right] \mathbf{H}^{T}+\mathbf{H} E\left[\mathbf{t}(n) \mathbf{t}^{T}(n)\right] \mathbf{H}^{T}
$$

onde $\alpha_{m}^{2}$ é a variância da marca d'água, $\mathbf{m}(n)$ e $\mathbf{t}(n)$ são, respectivamente, os vetores com $M$ elementos relativos à marca d'água e ao sinal de informação; $\mathbf{H} \in \Re^{(M+N+1) \times(M+1)}$ é uma matriz de convolução do sistema, e $M$ é a ordem do equalizador. Assume-se o sistema como sendo FIR com função de transferência de ordem $N$ e coeficientes $\mathbf{h}=\left[h_{0} \cdots h_{N-1}\right]^{T}$. $\mathrm{O}$ vetor de correlação cruzada $\mathbf{p}$ no equalizador é definido como:

$$
\mathbf{p}=\alpha_{m}^{2} \mathbf{H} E\left[\mathbf{m}(n) m^{*}(n-d)\right]
$$

onde $d$ é o atraso ótimo de equalização. O ponto de mínimo global para a função custo $J$ será:

$$
\begin{aligned}
\mathbf{w}_{o}= & \mathbf{R}^{-1} \mathbf{p}=\alpha_{m}^{2}\left(\alpha_{m}^{2} \mathbf{H} E\left[\mathbf{m}(n) \mathbf{m}^{T}(n)\right] \mathbf{H}^{T}+\right. \\
& \left.\mathbf{H} E\left[\mathbf{t}(n) \mathbf{t}^{T}(n)\right] \mathbf{H}^{T}\right)^{-1} \mathbf{H} E\left[\mathbf{m}(n) m^{*}(n-d)\right]
\end{aligned}
$$

A presença do termo $\mathbf{t}(n)$ na equação (3) implica em uma dependência da solução de Wiener com o sinal de informação.

Devido à marca d'água ter espectro branco e ser normalizada, o termo $E\left[\mathbf{m}(n) \mathbf{m}^{T}(n)\right]$ torna-se uma matriz identidade. De maneira similar, quando assumimos que o sinal de transmissão é descorrelacionado, o termo $E\left[\mathbf{t}(n) \mathbf{t}^{T}(n)\right]$ é também uma matriz identidade multiplicada pela variância $\sigma_{t}^{2}$ do sinal $\mathbf{t}(n)$. Com isso, a matriz $\mathbf{R}$ pode ser reescrita como:

$$
\mathbf{R}=\alpha_{m}^{2} \mathbf{H} \mathbf{H}^{T}+\sigma_{t}^{2} \mathbf{H} \mathbf{H}^{T}=\left(\alpha_{m}^{2}+\sigma_{t}^{2}\right) \mathbf{H} \mathbf{H}^{T}
$$

Neste caso, $\mathbf{R}$ não está mais subordinada ao sinal $\mathbf{t}(n)$ (com exceção da variância $\sigma_{t}^{2}$, que pode ser estimada). Os coeficientes ótimos referentes à solução de Wiener podem ser expressos como:

$$
\mathbf{w}_{o}=\mathbf{R}^{-1} \mathbf{p}=\frac{\alpha_{m}^{2}}{\alpha_{m}^{2}+\sigma_{t}^{2}}\left(\mathbf{H H}^{T}\right)^{-1} \mathbf{H} E\left[\mathbf{m}(n) m^{*}(n-d)\right]
$$

Exceto por um fator de escala, os coeficientes do equalizador tendem a um ponto que inverte a resposta impulsiva do sistema.

Para o caso de sinais de informação correlacionados, teremos:

$$
\mathbf{R}=\alpha_{m}^{2} \mathbf{H H}^{T}+\mathbf{H} E\left[\mathbf{t}(n) \mathbf{t}^{T}(n)\right] \mathbf{H}^{T}
$$

Para que a convergência aproxime-se da solução ótima de Wiener, pode-se utilizar um método de branqueamento. A figura 1 introduz um filtro de erro de predição na saída do equalizador. Este filtro tem como objetivo branquear o sinal $y(n)$ através da filtragem de suas componentes redundantes (periódicas). A saída do preditor é composta pela parte correlacionada do sinal $y(n)$. Através do cálculo da diferença entre $y(n)$ e o sinal na saída do preditor, obtemos $y^{\prime}(n)$, que corresponde às componentes descorrelacionadas na saída do equalizador. Tem-se assim:

$$
y^{\prime}(n)=y(n)-\sum_{k=1}^{P} w_{f, k}^{*} y(n-k-\Delta)
$$

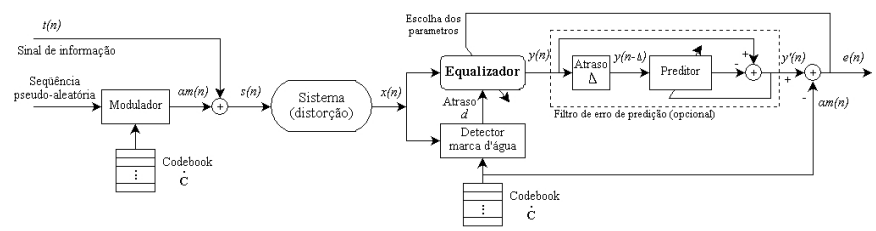

Fig. 1. Esquema de equalização utilizando marca d'água

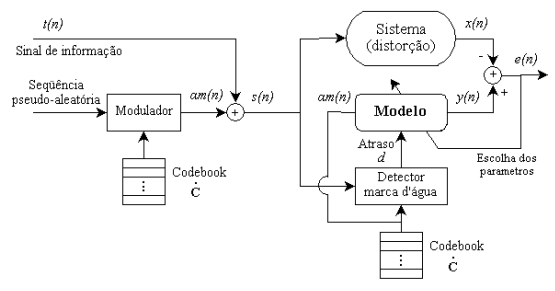

Fig. 2. Esquema de identificação utilizando marca d'água

onde $w_{f, k}^{*}$ são os coeficientes do preditor com $P$ elementos de atraso. Como a função custo do equalizador tende a um mínimo, o sinal de erro $y^{\prime}(n)$ tende às componentes descorrelacionadas do sinal de informação, mais a marca d'água (que é um sinal descorrelacionado). $\mathrm{O}$ atraso $\Delta$ deve ser grande o suficiente para que o filtro de predição seja capaz de remover a correlação do sinal $y(n)$.

\section{B. Identificação Adaptativa Baseada em Marca d'Água}

A mesma marca d'água é transmitida continuamente, sobreposta ao sinal de informação, utilizando a técnica de espalhamento espectral. A marca d'água escalonada é utilizada como sinal de referência no filtro equalizador adaptativo, produzindo uma função custo $J=E\left[|y(n)-d(n)|^{2}\right]$. A solução é obtida através da minimização da função custo com respeito aos coeficientes $\mathbf{w}$ do modelo.

A superfície de erro do critério de Wiener na forma canônica para este sistema pode ser escrita da seguinte forma [9]:

$J(\mathbf{w})=\sigma_{x}^{2}-\mathbf{p}_{m}^{T} \mathbf{R}_{m}^{-1} \mathbf{p}_{m}+\left(\mathbf{w}-\mathbf{R}_{m}^{-1} \mathbf{p}_{m}\right)^{T} \mathbf{R}_{m}\left(\mathbf{w}-\mathbf{R}_{m}^{-1} \mathbf{p}_{m}\right)$

onde $\sigma_{x}^{2}$ é a variância do sinal de referência, e os termos $\mathbf{R}_{m}$ e $\mathbf{p}_{m}$ expressam, respectivamente, a autocorrelação e a correlação cruzada do sinal de marca d'água.

Para obter-se o ponto de mínimo na equação (8), o termo $\left(\mathbf{w}-\mathbf{R}_{m}^{-1} \mathbf{p}_{m}\right)$ deve ser igualado a zero:

$$
\mathbf{w}_{0}-\mathbf{R}_{m}^{-1} \mathbf{p}_{m}=0 \quad \Rightarrow \quad \mathbf{w}_{0}=\mathbf{R}_{m}^{-1} \mathbf{p}_{m}
$$

Observa-se que o ponto de mínimo obtido, mostrado na equação (9), depende apenas das características do sinal de marca d'água, bastando o conhecimento prévio deste sinal para que seja possível o ajuste dos coeficientes do modelo. A figura 2 ilustra este esquema.

\section{MÉTODOS DE RESSINCRONIZAÇÃO}

\section{A. Seqüência de Blocos}

Para encontrar os deslocamentos dos símbolos da marca d'água no receptor, consideramos a marca como uma 
seqüência de treinamento conhecida e presente ao longo de todo o sinal transmitido [7], [8]. O receptor não conhece o início exato da transmissão, sendo necessário um método de sincronização inicial. Além disso, um método de ressincronização também se faz necessário ao longo de toda a transmissão.

Tanto a sincronização inicial como a ressincronização contínua são obtidas através do uso de uma seqüência de treinamento conhecida pelo receptor, codificada através dos símbolos que compõem a marca d'água. Estes símbolos são associados a sinais construídos através de um gerador de seqüência pseudo-aleatória escalonada. Um bloco da marca d'água é definido como uma seqüência de $N$ símbolos, e a marca d'água é obtida através da sucessão de múltiplas cópias deste bloco. A marca d'água assim obtida possui as características de um sinal quase branco.

A seqüência de símbolos presente no bloco da marca d'água é dada por: $\mathbf{m}_{\alpha}=\left[m_{\alpha}(0), m_{\alpha}(1), \ldots, m_{\alpha}(N-1)\right]$, onde $N$ expressa a quantidade de símbolos do bloco e $\alpha \in\{0,1\}$ é a estimativa do fator de atenuação para a relação de potência sinal-marca d'água (SWR, do inglês signal to watermark ratio) utilizada no sistema. Por simplicidade, consideramos que a janela de análise tem o mesmo comprimento do bloco; no entanto, nada impede que ambos tenham tamanhos diferentes.

O ponto exato de início do bloco é desconhecido pelo receptor. $\mathrm{Na}$ fase de detecção, uma janela deslizante é utilizada para calcular as $N$ medidas de correlação para todos os símbolos que formam o bloco da marca d'água $m_{\alpha}(n)$ :

$$
r(\lambda, j)=\left|\sum_{n=0}^{N-1} x(j N+n+\lambda) m_{\alpha}(n)\right|
$$

onde $\lambda \in[-\Lambda, \Lambda-1]$ é o deslocamento da janela deslizante $(\Lambda=N / 2$ para $N$ par) e $x(n)$ é o sinal marcado. Com isso, podemos construir uma matriz $\mathbf{A}=\left\{\beta_{\lambda, j}\right\}$ ( $j$ representa diferentes janelas de análise) cuja linha corresponde ao deslocamento $\lambda$ e cuja coluna corresponde à posição $j$ para cada janela de análise. Dessa forma, A conterá as maiores medidas de correlação para cada deslocamento da janela em relação à seqüência de símbolos do bloco que compõe a marca d'água.

Apresentaremos na seção IV dois diferentes algoritmos capazes de localizar o caminho através das células da matriz A referente ao atraso ótimo dos símbolos de um bloco da marca d'água, partindo da primeira coluna $(j=0)$ até a última $(j=J-1)$. Isto resulta em um conjunto de $J$ valores para $\lambda,\left[\hat{\lambda}_{0} \ldots \hat{\lambda}_{J-1}\right]$, um para cada deslocamento da janela de análise. $\mathrm{O}$ uso de métodos robustos para escolha do melhor deslocamento na matriz $\mathbf{A}$ faz-se necessário devido à baixa potência da marca d'água em relação ao sinal de informação, necessária para que a marca d'água seja transparente (i.e. seja vista como um ruído de baixa intensidade por receptores legados não preparados para detectá-la). Com isso, picos espúrios de correlação podem surgir, não correspondendo ao atraso ótimo, conforme ilustrado na Fig. 3.

\section{B. Seqüência de Vetores de Codebook}

Um codebook $\dot{\mathbf{C}}$ pode ser usado para gerar a marca d'água $w(n)$, ao invés de um único bloco [4]. Este code-

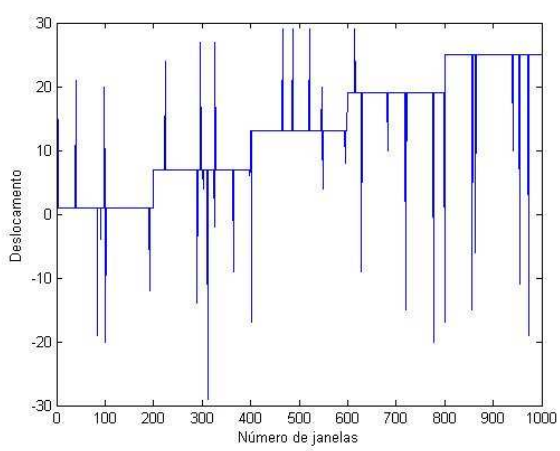

Fig. 3. Deslocamentos de janela deslizante correspondentes à máxima correlação para o bloco da marca d'água. Neste exemplo, 5 amostras são apagadas a cada 200 janelas.

book contém $\dot{\mathbf{u}}_{k}=\left[\dot{u}_{k}(0) \cdots \dot{u}_{k}(N-1)\right](k \in[0, \dot{K}-1])$ vetores associados a $\dot{K}$ símbolos. A seqüência de símbolos $\mathbf{z}=\left[z_{0} \cdots z_{M-1}\right]$ da marca d'água é obtida de acordo com a regra

$$
z_{j}=j \bmod \dot{K}
$$

onde $z_{j}$ é o $j$-ésimo símbolo na seqüência da marca d'água $(j \in[0, J-1])$, sendo esta seqüência conhecida no detector. A marca d'água $w(n)$ é construída através da concatenação sucessiva de vetores associados aos símbolos na seqüência $\mathbf{z}$.

$\mathrm{Na}$ detecção, uma janela deslizante é usada para calcular $N$ medidas de correlação para cada um dos $J$ símbolos na marca d'água $w(n)$ e para cada $\dot{K}$ vetores no codebook $\dot{\mathbf{C}}$ :

$$
\dot{r}(\lambda, k, j)=\left|\sum_{n=0}^{N-1} x(j N+n+\lambda) \dot{u}_{k}(n)\right|
$$

onde $\lambda \in[-\Lambda, \Lambda-1]$ é o deslocamento da janela deslizante ( $\Lambda=N / 2$ para $N$ par) e $x(n)$ é o sinal marcado. Através da maximização em $k$, podemos construir duas matrizes: $\mathbf{A}=\left\{\beta_{\lambda, j}\right\}$ e $\mathbf{B}=\left\{\chi_{\lambda, j}\right\}$ ( $j$ representa diferentes janelas de análise) cujas linhas correspondem ao deslocamento $\lambda$ e cujas colunas correspondem à posição $j$ para cada símbolo na seqüência.

$$
\begin{gathered}
\beta_{\lambda, j}=\max _{k} \dot{r}(\lambda, k, j) \\
\chi_{\lambda, j}=\arg \max _{k} \dot{r}(\lambda, k, j)
\end{gathered}
$$

Dessa forma, A conterá as maiores medidas de correlação para cada deslocamento e cada posição na seqüência de símbolos e B conterá o símbolo correspondente no codebook $\dot{\mathbf{C}}$.

Apresentaremos na seção IV um algoritmo de programação dinâmica usado para localizar o caminho ótimo nas células das matrizes $\mathbf{A}$ e $\mathbf{B}$, partindo da primeira coluna $(j=0)$ até a última $(j=J-1)$. O processo de escolha do caminho ótimo é ilustrado na Fig. 4 para a matriz B. O algoritmo leva em conta a ordem de símbolos esperada e as medidas máximas de correlação, resultando em um conjunto de $J$ valores para $\lambda,\left[\hat{\lambda}_{0} \ldots \hat{\lambda}_{J-1}\right]$. 


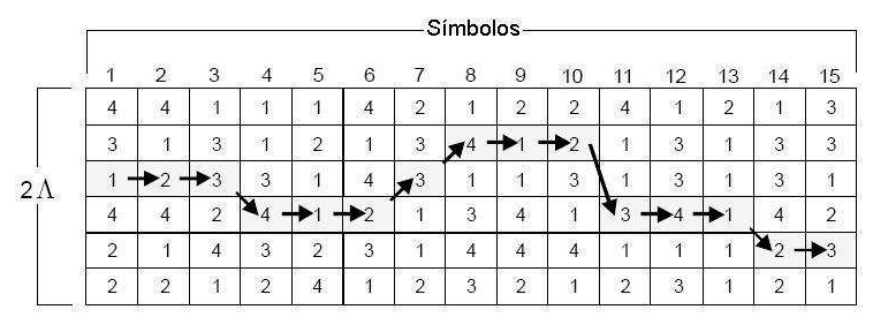

Fig. 4. Exemplo de busca do caminho ótimo na matriz $\mathbf{B}$.

\section{Algoritmos de Ressincronização}

\section{A. Média de Janelas de Análise}

Uma maneira simples e intuitiva para encontrar o melhor atraso na matriz A é calcular o valor médio de $t$ diferentes colunas do conjunto de janelas $J$. Assim, mesmo que haja picos espúrios de correlação, estes tenderão a ser neutralizados pelo cálculo da média, por apresentarem-se de forma aleatória e não polarizada. $\mathrm{O}$ algoritmo resultante é descrito a seguir:

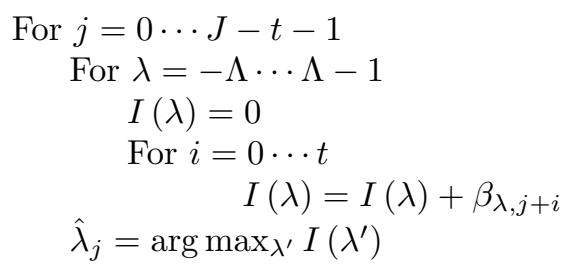

O resultado do algoritmo é um conjunto de deslocamentos $\left[\hat{\lambda}_{0} \ldots \hat{\lambda}_{J-t-1}\right]$ correspondentes ao caminho ótimo.

Apesar de o método funcionar bem para baixos valores de SWR, ele apresenta problemas quando o sistema de marca d'água utiliza valores mais altos para esta relação, pois nesta situação a quantidade de picos espúrios de correlação aumenta significativamente. Para que a média entre as diferentes janelas seja significativa, são necessários valores grandes de $t$, acarretando atrasos no sistema. Dependendo da aplicação, estes atrasos podem ser inaceitáveis, principalmente em sistemas de tempo real que requerem uma constante verificação de sincronismo.

Apesar das desvantagens mencionadas, este método pode ser muito eficiente para a etapa de sincronização inicial.

\section{B. Otimização Através de Programação Dinâmica}

1) Função Custo para Seqüência de Blocos: Para determinar o deslocamento da janela deslizante que melhor corresponde à localização de um dado símbolo, pode-se utilizar um algoritmo de programação dinâmica [5], [6]. O processo de otimização minimiza uma função custo calculada em termos da matriz $\mathbf{A}=\left\{\beta_{\lambda, j}\right\}$. Através de um conjunto de $J$ valores definidos para o deslocamento $\lambda,\left[\hat{\lambda}_{0} \ldots \hat{\lambda}_{J-1}\right]$, determinase um caminho na matriz $\mathbf{A}$ através do qual a sequiência de símbolos da marca d'água pode ser obtida.

A função custo $c\left(\lambda, \lambda^{\prime}, j\right)$ para passar de um determinado estado $\left[\lambda^{\prime}, j-1\right]$ ao estado $[\lambda, j]$ é composta por dois termos:

$$
c\left(\lambda, \lambda^{\prime}, j\right)=c_{1}\left(\lambda, \lambda^{\prime}, j\right)+c_{2}(\lambda, j)
$$

$\mathrm{O}$ primeiro termo penaliza as chances do deslocamento $\lambda$ passar do estado $\left[\lambda^{\prime}, j-1\right]$ para o estado $[\lambda, j]$, pois o deslocamento deve normalmente permanecer na mesma linha quando a seqüência de treinamento é respeitada, reduzindo assim a ocorrência de deslocamentos provocados por picos espúrios de intercorrelação:

$$
c_{1}\left(\lambda, \lambda^{\prime}, j\right)=\eta_{j}\left(\lambda-\lambda^{\prime}\right)^{2}
$$

onde o termo quadrático impõe uma penalidade que aumenta rapidamente com o deslocamento de $\lambda$ para $\lambda^{\prime}$ (justificado pelo fato de que longos segmentos do sinal normalmente não são apagados ou adicionados ao sinal marcado). O fator $\eta_{j}$ é definido como:

$$
\eta_{j}= \begin{cases}\eta_{j-1}+\kappa_{1} & \text { se } \lambda_{j} \neq \lambda_{j-1} \\ \max \left(\eta_{j-1}-\kappa_{2}, \eta_{0}\right) & \text { outro }\end{cases}
$$

sendo $\kappa_{1}$ e $\kappa_{2}$ constantes positivas (geralmente $\kappa_{1}>\kappa_{2}$ ), $\lambda_{j}$ o número correspondente à coluna $j$ no caminho atual, e $\eta_{0}$ inicializado com um valor positivo. Esta definição evita caminhos com percurso em ziguezague, pois $\eta_{j}$ tende a crescer nesta situação.

O segundo termo na definição da função custo (15) está relacionado à medida de correlação presente na matriz $\mathbf{A}$ :

$$
c_{2}(\lambda, j)=\rho\left(1-\frac{\beta_{\lambda, j}}{\max _{\tilde{\lambda}} \beta_{\tilde{\lambda}, j}}\right)
$$

onde $\rho$ é uma constante positiva. A expressão entre parênteses assume valores entre 0 (quando o deslocamento $\lambda$ corresponde ao maior valor de correlação) e 1 (quando a correlação para um deslocamento $\lambda$ é nulo). Esta definição penaliza deslocamentos $\lambda$ que apresentam baixos valores de correlação.

2) Função Custo para Seqüência de Vetores de Codebook: Para determinar o deslocamento da janela deslizante que melhor correspondente a localização do símbolo atual, o processo de otimização minimiza uma função custo calculada em termos das matrizes $\mathbf{A}=\left\{\beta_{\lambda, j}\right\}$ e $\mathbf{B}=\left\{\chi_{\lambda, j}\right\}$. Através de um conjunto de $J$ valores definidos para o deslocamento $\lambda,\left[\hat{\lambda}_{0} \ldots \hat{\lambda}_{J-1}\right]$, determina-se um caminho nas matrizes $\mathbf{A} \mathrm{e}$ B através do qual a seqüência de símbolos da marca d'água pode ser obtida.

A função custo $c\left(\lambda, \lambda^{\prime}, j\right)$ para passar de um determinado estado $\left[\lambda^{\prime}, j-1\right]$ para o estado $[\lambda, j]$ é composta, neste caso, por três termos:

$$
c\left(\lambda, \lambda^{\prime}, j\right)=c_{1}\left(\lambda, \lambda^{\prime}, j\right)+c_{2}(\lambda, j)+c_{3}\left(\lambda, \lambda^{\prime}, j\right)
$$

Os dois primeiros termos são idênticos aos definidos na função custo (15). O terceiro termo, responsável por reforçar a observância da sequiência de símbolos da marca d'água, obtida através de vetores do codebook, é definido como

$c_{3}\left(\lambda, \lambda^{\prime}, j\right)=\left\{\begin{array}{l}\psi\left(\chi_{\lambda, j}-\chi_{\lambda^{\prime}, j-1}-1\right) \quad \chi_{\lambda, j} \geq \chi_{\lambda^{\prime}, j-1} \\ \psi\left(\chi_{\lambda, j}-\chi_{\lambda^{\prime}, j-1}-1+\dot{K}\right)^{\text {outros }}\end{array}\right.$ 
onde $\psi$ é uma constante e $\dot{K}$ o número de vetores do codebook. Se a seqüência de símbolos da marca d'água é respeitada, este custo é nulo; caso contrário, o custo é proporcional ao salto da seqüência da marca d'água. Esta definição é justificada pelo fato de que, em geral, longos trechos não são inseridos ou apagados do sinal transmitido.

3) Algoritmo de Otimização: Define-se o custo acumulado $C(\lambda, j)$ como o custo mínimo para passar para o estado $[\lambda, j]$ partindo do estado na primeira coluna $(j=0)$. Este custo é inicializado em 0 para $j=0$ e todo $\lambda$. O algoritmo de otimização é descrito a seguir:

$$
\begin{aligned}
& \text { For } j=1 \cdots J-1 \\
& \text { For } \lambda=-\Lambda \cdots \Lambda-1 \\
& \quad \lambda=\arg \min _{\lambda^{\prime}}\left[C\left(\lambda^{\prime}, j-1\right)+c\left(\lambda, \lambda^{\prime}, j\right)\right] \\
& \\
& \quad C(\lambda, j)=C(\bar{\lambda}, j-1)+c(\lambda, \bar{\lambda}, j) \\
& \quad I(\lambda, j)=\bar{\lambda} \\
& \hat{\lambda}_{J-1}=\arg \min _{\tilde{\lambda}}[C(\tilde{\lambda}, J-1)] \\
& \text { For } j=J-2 \cdots 0 \\
& \hat{\lambda}_{j}=I\left(\lambda_{j+1}, j+1\right)
\end{aligned}
$$

O resultado do algoritmo é um conjunto de deslocamentos $\left[\hat{\lambda}_{0} \ldots \hat{\lambda}_{J-1}\right]$ correspondentes ao caminho ótimo.

\section{Simulações e Resultados}

Para analisar o desempenho dos algoritmos propostos para ressincronização, dois sinais foram utilizados. O primeiro é um sinal digital, descorrelacionado, constituído de amostras i.i.d. e pertencente a uma constelação 2-PAM ou 2-PSK com módulo unitário; o segundo é um sinal de fala, "svega"(uma versão capela de "Tom's diner", de Suzanne Vega), fortemente correlacionado. A relação SWR foi ajustada em $20 \mathrm{~dB}$. Considerouse que não há ruído aditivo no sistema.

Para ilustrar a perda de sincronismo, 5 amostras foram retiradas do sinal a cada 200 janelas, forçando o sistema a ressincronizar a detecção da marca d'água. Adotamos um sistema de teste com fase não-mínima modelado como um filtro linear com a função de transferência $\mathrm{H}(z)=1+1.2 z^{-1}$ $0.3 z^{-2}+0.8 z^{-3}$. Foram utilizadas janelas com comprimento $N=512$, com um deslocamento máximo $\Lambda=256$ para a janela deslizante.

Os dois métodos de otimização foram utilizados para ressincronização. $\mathrm{O}$ algoritmo de média de janelas utilizou o valor constante $t=10$. A otimização através de programação dinâmica utilizou os valores constantes $\psi=\Lambda, \eta_{0}=1$, $\kappa_{1}=5, \kappa_{2}=1$ e $\rho=10$. Estes parâmetros foram ajustados empiricamente.

As figuras 5 e 6 apresentam os resultados para os dois sinais utilizando os algoritmos propostos. As figuras 5(a) e 6(a) ilustram os maiores valores de correlação para a matriz A. Nota-se que existem diversos picos espúrios de correlação, dificultando a determinação do atraso ótimo de sincronismo. As figuras 5(b) e 6(b) apresentam o resultado do algoritmo utilizando média entre diferentes janelas. Nota-se que o método não foi capaz de determinar com exatidão o caminho ótimo. As figuras 5(c) e 6(c) mostram que o algoritmo de programação dinâmica utilizando bloco foi capaz de encontrar o deslocamento ótimo

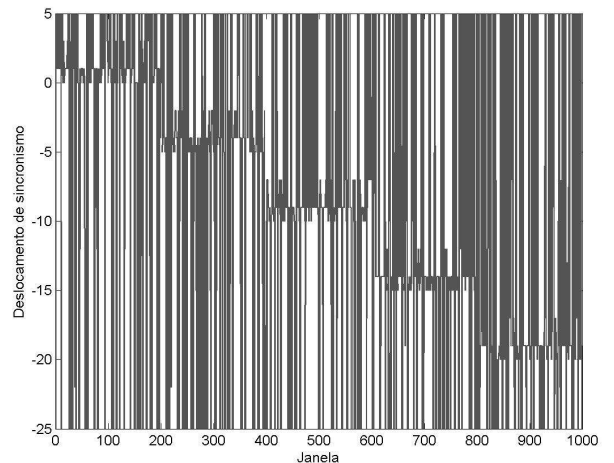

(a)

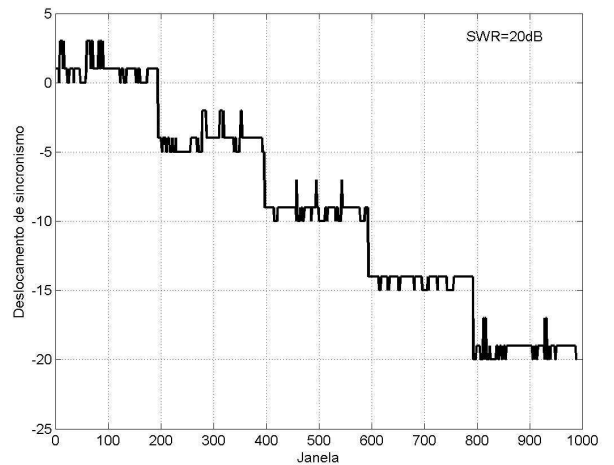

(b)

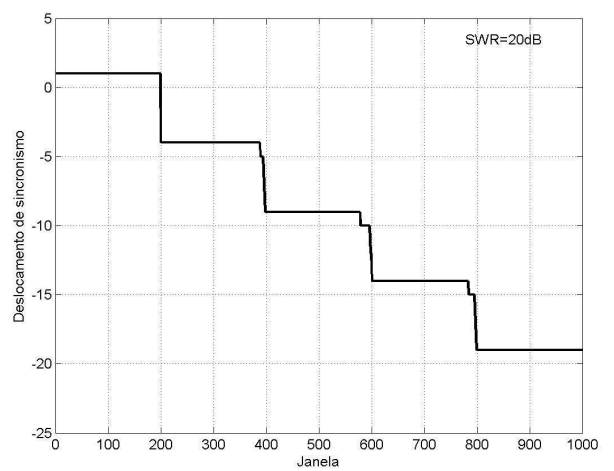

(c)

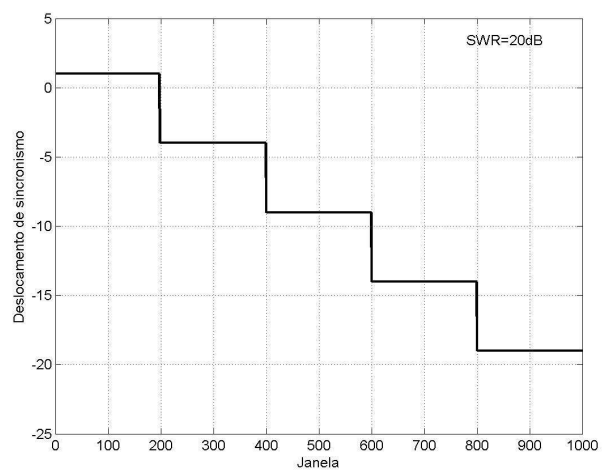

(d)

Fig. 5. Desempenho dos algoritmos de sincronismo com sinal digital 5(a) picos espúrios de correlação; 5(b) média de janelas; 5(c) programação dinâmica utilizando bloco; $5(\mathrm{~d})$ programação dinâmica utilizando codebook. 


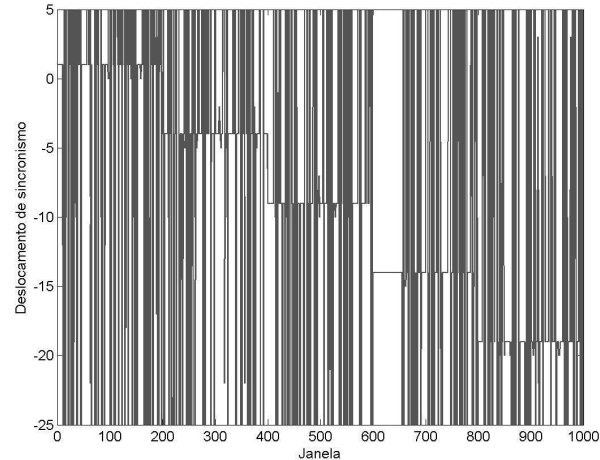

(a)

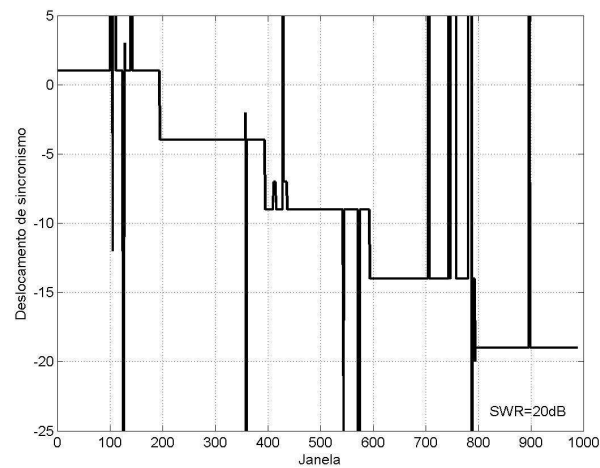

(b)

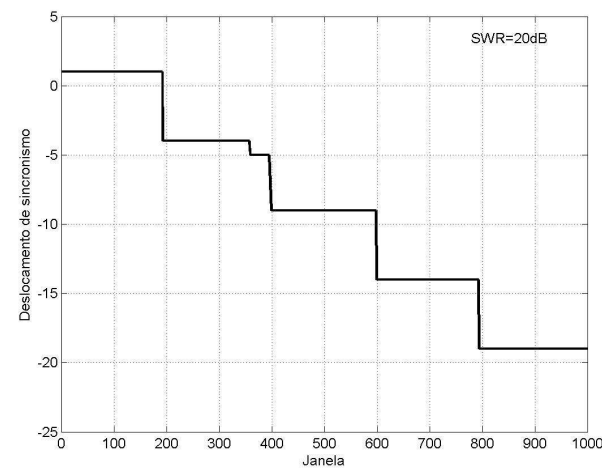

(c)

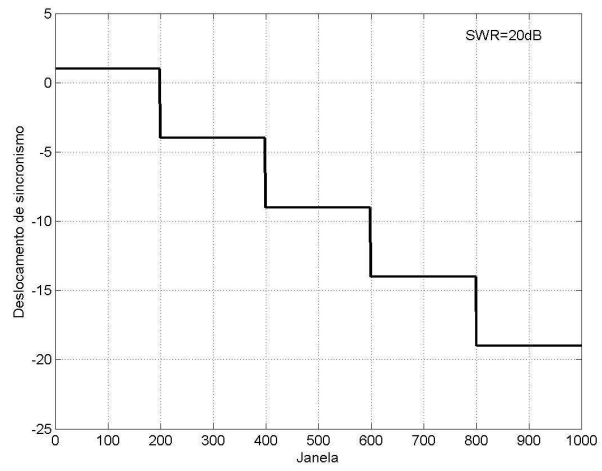

(d)

Fig. 6. Desempenho dos algoritmos de sincronismo com sinal de áudio: 6(a) picos espúrios de correlação; 5(b) média de janelas; 5(c) programação dinâmica utilizando bloco; 5(d) programação dinâmica utilizando codebook. para ambos os sinais, porém apresentou problemas na transição de deslocamentos, levando algum tempo para ajustar-se à nova condição de sincronismo. As figuras 5(d) e 6(d) mostram que o algoritmo de programação dinâmica utilizando codebook foi capaz de rastrear o sincronismo de forma bastante eficiente, inclusive nos momentos de transição.

\section{CONCLUSÕES}

Neste trabalho, apresentamos dois métodos de sincronismo aplicáveis aos sistemas de identificação e equalização que utilizam marca d'água. Os métodos são baseados no uso de uma sequência de treinamento formada pela própria informação da marca d'água. Estes métodos revertem os efeitos de uma ampla classe de ataques de dessincronização. Além disso, são capazes de monitorar o sincronismo continuamente, ao longo de todo o sinal recebido. Foi abordado apenas o caso de ataques não intencionais, provocados por distorções impostas pela transmissão do sinal marcado através de um sistema linear. Além de distorções lineares, foi considerada a situação de perda de trechos do sinal transmitido, causando modificações no tamanho do sinal na escala temporal.

Para determinação dos atrasos ótimos do sistema, foram propostos dois algoritmos. O primeiro baseia-se na média de diferentes janelas de análise do sinal recebido; já o segundo baseia-se em técnicas de programação dinâmica.

Os resultados experimentais mostram que os métodos foram bem-sucedidos ao encontrar o atraso inicial requerido para o sincronismo. O segundo método apresentado, baseado em programação dinâmica, é também capaz de ressincronizar continuamente o sinal recebido, identificando rapidamente falhas no canal de comunicação que causem perda de sincronismo.

Nas próximas etapas deste trabalho, prevê-se o estudo do comportamento dos métodos propostos frente a ataques mais severos, tais como filtragem não-linear, codificação/decodificação e reamostragem. Além disso, no caso de aplicações de áudio e voz, será considerado o uso de modelos psico-acústicos para aumentar a energia da marca d'água sem introdução de degradações perceptíveis.

\section{REFERÊNCIAS}

[1] C. Neubauer, J. Herre, Advanced watermarking and its applications, 109th AES Convention, Los Angeles, September 2000.

[2] M. Uliani Neto, Leandro de C. T. Gomes, João Marcos T. Romano, and Madeleine Bonnet, Adaptive equalization based on watermarking, VI International Telecommunications Symposium (ITS2006), September, Fortaleza, Brazil, 2006.

[3] S. Haykin, Adaptive filter theory, third edition, Prentice Hall, 1996.

[4] L. de C. T. Gomes, E. Gómez, N. Moreau, Resynchronization methods for audio watermarking, Proceedings of 111th AES Convention, New York, USA, November, 2001.

[5] G. D. Forney, The Viterbi algorithm, Proc. of the IEEE, vol. 61, pag. 268-278, March, 1973.

[6] D. P. Bertsekas, Dynamic Programming and optimal Control, Athena Scientific, second edition, 2000.

[7] E. Gómez, Tatouage de signaux de musique (méthodes de synchronisation), technical report (DEA ATIAM), Université de la Méditerranée / ENST, Paris, France, July, 2000.

[8] N. Moreau, P. Dymarski, and L. de C.T. Gomes, Tatouage audio : une réponse à une attaque désynchronisante, CORESA, Poitiers, France, October, 2000.

[9] M. Uliani Neto, Identificação e Equalização em Sistemas Adaptativos Utilizando Marca d'Água Digital, Tese de Mestrado, Unicamp, defesa prevista para $2^{\circ}$ semestre de 2007. 